'llu. Revista de Ciencias de las Religiones

ISSN: $1135-4712$

http://dx.doi.org/10.5209/ILUR.53848

\title{
Mitos, hitos y gritos en la internacionalización del yoga ${ }^{1}$
}

\author{
Adrián Muñoz
}

Recibido: 19 de febrero de 2016 / Aceptado: 19 de abril de 2016

Resumen. El yoga posee una carrera sólida y larga. El paso natural era convertirse en un artículo oficial del discurso global sobre salud y bienestar, concretado en el primer Día Internacional del Yoga. Sin embargo, existen diversas ideas preconcebidas sobre la práctica, además de implicaciones políticas y sociales involucradas que merecen cuestionarse. ¿Qué es el yoga y a quién le pertenece? ¿Qué implicaciones tiene esto para el escenario religioso de la India? Dicha celebración, ¿acorta las distancias entre diferentes mundos culturales y geopolíticos? ¿Hay alguna agenda política detrás? El presente artículo ofrecerá un recuento del Día Internacional del Yoga, así como una mirada crítica en varios de estos puntos de discusión, invitando a un debate amplio.

Palabras clave: Yoga moderno; Día Internacional del Yoga; Religiones de India; Narendra Modi; Paz mundial.

\section{[en] Myths, milestones, and claims: the internationalization of yoga}

\begin{abstract}
The trajectory of yoga has been long and steady. It was only natural that it would become an official item in the global discourse on well-being and health, leading to an International Day of Yoga. Nevertheless, there are various preconceptions about the practice, as well as different political and social issues that are worth querying. What and whose is yoga? What sort of disputes does this bear in the religious arena within India? Does the novel international celebration bridge the gap between different cultural and geopolitical worlds? Is there an implied political agenda? This paper will offer both a brief account of the International Day of Yoga, and a critical view on all these issues with a view to foster a wider debate.
\end{abstract}

Keywords: Modern Yoga; International Day of Yoga; Indian Religions; Narendra Modi; World peace.

Sumario. 1. Introducción. 2. Problemática y trasfondo. 2.1. Problemática. 2.2. Trasfondo: la campaña por el IDY. 3. Reacciones y conflicto. 4. La propaganda: el discurso y las nociones sobre el yoga. 5. Conclusiones: cuestiones para seguir considerando. 6. Bibliografía.

Cómo citar: Muñoz, A., (2016), Mitos, hitos y gritos en la internacionalización del yoga, en 'Ilu. Revista de Ciencias de las Religiones 21, 115-128.

\footnotetext{
1 Los primeros apuntes para este texto comenzaron justo después del 21 de junio de 2015. Una versión preliminar de este artículo se presentó en el XV Congreso Internacional de la Asociación Latinoamericana de Estudios de Asia y África, celebrado en Santiago de Chile del 11 al 14 de enero de 2016.

2 Centro de Estudios de Asia y África, El Colegio de México (México).

E-mail: amunoz@colmex.mx
} 


\section{Introducción}

El yoga, como práctica físico-espiritual, posee una carrera sólida y larga. El paso natural en su evolución era convertirse, de manera oficial, en un artículo más del discurso global de salud y bienestar, en virtud de sus asociaciones terapéuticas y saludables. Así, en 2015 se celebró el primer Día Internacional del Yoga, avalado por la ONU. Sin embargo, existen diversas ideas preconcebidas y malentendidos en lo que se refiere a la práctica, todo lo cual ha producido una concepción bastante sui generis del yoga o, por ponerlo de otra forma, ha derivado en una nueva modalidad del yoga, una forma moderna. Esta forma moderna de yoga combina, sin un criterio demasiado claro, expresiones más viejas que no siempre estuvieron en concordancia. Al mismo tiempo, la búsqueda de la instauración de un Día Internacional del Yoga también posee algunas implicaciones políticas y sociales que no se perciben a primera vista. En este contexto, es pertinente reflexionar sobre algunas interrogantes: ¿Qué es el yoga y a quién le pertenece? ¿Qué implicaciones tiene esto para el escenario religioso de la India? Dicha celebración, ¿acorta las distancias entre diferentes mundos culturales y geopolíticos? ¿Tiene que ver con alguna agenda política?

El pasado 21 de junio de 2015 fue una fecha histórica: se celebró por primera vez el Día Internacional del Yoga (antarrāștrīy yog divas). Para citar un ejemplo: al igual que en ciudades como Nueva York, París, Buenos Aires o Madrid, varios cientos de personas se dieron cita en una "mega clase" de yoga en el Paseo de la Reforma de la Ciudad de México, junto al Ángel de la Independencia: los cientos de asistentes, previa inauguración oficial a manos del jefe de Gobierno de la capital mexicana, acompañado del embajador de la India en México y el director del Instituto del Deporte, dieron inicio a una semana del yoga, una serie de actividades alusivas que se extendieron hasta el 28 de junio. Conferencias, talleres, clases y hasta espectáculos de "yoga-trance-dance" rindieron tributo al yoga, esa añeja tradición de la India.

\section{Problemática y trasfondo}

\subsection{Problemática}

Todo ello resulta interesante por varias razones, no sólo por el motivo central de insertar el yoga en un discurso global de manera oficial. Así, pues, a las actividades realizadas en México y otras partes del orbe hay que agregar otras circunstancias y factores para poder comprender su importancia. En el Times Square de Nueva York, la práctica del yoga convocó el mentado domingo a miles de personas y duró prácticamente todo el día. Sin embargo, ésta no fue la primera sino la decimotercera ocasión en que la urbe neoyorquina conmemoró el yoga. Los matices variaron de ciudad a ciudad, pero lo que se vivió desde India ofrece varias aristas dignas de analizarse, pues las facetas más problemáticas tuvieron lugar allí, en la tierra natal del yoga.

El punto de congregación más importante en India para celebrar el primer Día Internacional del Yoga (IDY, por sus siglas en inglés) fue, desde luego, Nueva Delhi, la capital india. Allí se reunió la exorbitante cantidad de 35.000 personas 
(algunas fuentes indican que fueron 45.000). ${ }^{3}$ Se realizaron veintiún āsanas, o posturas, durante media hora y el evento, desde luego, estuvo presidido por Narendra Modi, el actual primer ministro de la República de la India. Población civil, funcionarios públicos y oficinistas de todas las edades acudieron, en su mayoría, vestidos de blanco. Modi, además del color blanco, portó los colores nacionales. El primer ministro Modi, quien en un par de ocasiones había afirmado que no tomaría parte de los ejercicios y āsanas, tan pronto terminó de dar su discurso bajó del podio, buscó una estera disponible y practicó yoga con la multitud.

El impacto que este acto tuvo no es menor y se puede medir al menos en dos dimensiones: una interna y otra externa. En la dimensión interna, la participación de Modi permitió afianzar su papel de líder nacional, un líder que salvaguarda los valores tradicionales de la India. En la dimensión externa, de alguna manera esto fue una forma de demostrar que el primer ministro indio practica lo que predica, a saber: la cultivación del bienestar físico y mental. Para entender mejor qué implicaciones tiene todo esto, hay que considerar de manera comprensiva la campaña previa a favor de la instauración del IDY. Allí podremos encontrar factores que nos permitirán evaluar las cosas en un contexto más amplio.

\subsection{Trasfondo: la campaña por el IDY}

Muchos de los motivos, palabras y hechos que tuvieron lugar durante la campaña por el IDY no fueron casuales. Todos dan un matiz particular al trasfondo de la campaña y del discurso que la apoyó. Por ejemplo: B.K.S. Iyengar, uno de los llamados "padres del yoga moderno", falleció en agosto de 2014. Su deceso supuso una gran pérdida para practicantes de yogas posturales de todo el mundo. Un mes después de esta muerte, Modi hizo la petición formal a las Naciones Unidas para que instaurara un día mundial que conmemorara al yoga. El aura de Iyengar -y por extensión del yoga moderno- estaba aún en el aire y no era del todo fácil disociar una cosa de la otra. Como sea, todo parece indicar que, de cierta manera, la campaña se valió de la muerte de Iyengar para dar mayor impulso a su propaganda, más que convertirlo en una especie de santo internacional.

A finales de septiembre de 2014, Narendra Modi dio un discurso en la sede de las Naciones Unidas en Nueva York. Se trató de la 69 sesión de la Asamblea General de la ONU, a la cual fue invitado Modi tras varios periodos de veto en Estados Unidos, Gran Bretaña y parte de la Unión Europea a causa de los terribles y sangrientos sucesos en Gujarat cuando Modi fue ministro en jefe en dicho estado; dicha sanción concluyó en 2012 y 2013, durante el ascenso de la campaña política de Modi. En la sesión de septiembre de 2014 en Nueva York, además de referirse a su disposición de entablar diálogos amistosos con Pakistán, de combatir el terrorismo y de mejorar la cooperación multinacional, ${ }^{4}$ Narendra Modi habló también de la necesidad de cultivar un equilibrio entre el cuerpo y la mente en aras de lograr la paz. ${ }^{5}$

De manera inteligente, a continuación, Modi se refirió al tema del daño al ecosistema global. Y es allí, en ese punto del discurso, que el yoga, dijo el dirigente, justamente puede ayudarnos a conseguir esta armonía entre el ser humano y la naturaleza.

T. Ap 2015.

Modi 2014, 2.

Modi 2014, 3 ss. 
El ejemplo que debe tomarse es el de India, donde "el respeto por la naturaleza es una parte integral de la espiritualidad". Esto fue un giro sorpresivo: de acuerdo con Modi, el yoga puede ayudarnos a combatir el cambio climático. Por eso, concluyó, se debe instaurar un Día Internacional del Yoga.

Es cierto que la mayor parte del discurso no habla en pos del yoga, pero la manera en que el orador ha ido construyendo y desarrollando su argumento termina por eregir al yoga en una solución al cambio climático, pero también -por la insistencia en el combate articulado y colectivo contra el terrorismo- por presentarlo como una eficaz arma contra la violencia. El yoga se ofrece como una suerte de panacea a los problemas más agudos del orbe. La recomendación final de Modi fue eficaz. El 11 de diciembre de 2014, las Naciones Unidas decretaron el 21 de junio como el Día Internacional del Yoga, ${ }^{7}$ en buena medida gracias a las peticiones de Narendra Modi. ${ }^{8}$ Para honrar la primera celebración el 21 de junio de 2015, se hizo un llamado para realizar yoga en Rajpath, el bulevar políticamente más importante en Delhi y al cual acudiría Modi.

No es un asunto insignificante el énfasis que hizo Modi en las capacidades pacificadoras y mediadoras del yoga. Bien analizado, en su discurso parecen resonar las ideas de Iyengar o Pattabhi Jois, los célebres discípulos de Tirumalai Krishnamacharya, ya sea la "naturaleza de la paz suprema y la eterna dicha" de Jois, o "la verdadera unión de nuestra voluntad con la voluntad de Dios" de Iyengar. ${ }^{9}$ El discurso de Modi enaltecía de manera importante beneficios como la salud, la longevidad o el perfeccionamiento moral, ideas que recuerdan a lo que el propio Krishnamacharya subrayó en las primeras décadas del siglo XX: "El yoga brinda fortaleza al cuerpo, el yoga brinda salud y sólo el yoga puede brindarnos larga vida. El yoga ensancha nuestro intelecto. El yoga nos hace ricos. El yoga nos hace seres humanos. El yoga traerá de vuelta el honor y el respecto por la Madre India."10

Estos ecos le dan al discurso, de manera velada, tintes religiosos, por más que se presente al yoga como una herramienta secular y de beneficios accesibles a la población mundial. Esta apuesta necesitaba el imprimatur de un organismo internacional, por supuesto. Ban Ki-moon, el entonces secretario general de las Naciones Unidas, dijo poco antes del evento que el yoga "ofrece un medio sencillo, accesible e inclusivo para fomentar el bienestar y la salud física y espiritual." Asimismo, expresó que "promueve el respeto por nuestros semejantes y por el planeta que compartimos". ${ }^{11}$ El énfasis claramente recae en una política pacifista, al menos en el nivel del discurso. En ese mismo mensaje, Ban Ki-moon destacó los "beneficios holísticos" del yoga y "su inherente compatibilidad con los principios y valores de las Naciones Unidas".

\section{Reacciones y conflicto}

La apuesta por la armonía y el bienestar mundial conlleva elementos retóricos comunes a todo discurso internacional. Un proyecto como el de impulsar el yoga como

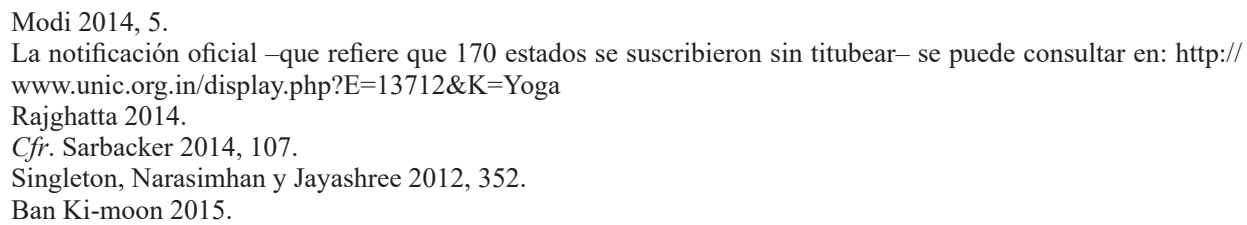


una herramienta de mejoramiento físico y mental parece, a primera vista, loable y bienvenido; después de todo, sin duda el yoga constituye una práctica saludable y el mundo se ha convertido en un sitio demasiado violento. No obstante, no todo ha sido miel sobre hojuelas, particularmente en el escenario político del sur de Asia. Si bien es cierto que la palabra "yoga" quiere decir "unión" -entre otros significados-, la realidad es que durante las semanas previas al 21 de junio de 2015 el evento resultó ser un elemento divisivo en el subcontinente asiático. Comenzó a levantar polémica y discusiones intensas en torno a la decisión de no incluir la famosa rutina conocida como Saludos al Sol (sürya-namaskār), con el argumento de que la actividad no debería tener tintes religiosos y confesionales, como alegó el Consejo Pan-indio para la Defensa del Derecho Personal Islámico (All India Muslim Personal Law Board, o AIMPLB).

Con todo, no debemos perder de vista que no todo el mundo islámico se ha opuesto al IDY; de los 177 países que suscribieron la iniciativa, 40 son musulmanes, ${ }^{12}$ un hecho que elogió Baba Ramdev, partidario de Modi y líder religioso del instituto Patanjali Yogpeeth, ubicado en Haridwar. ${ }^{13}$ ¿Por qué la población en India, que habita la tierra del yoga, se opuso entonces? Porque ello toca fibras sensibles que han sido heridas por las saetas del comunalismo, una enfermedad sociopolítica y culpable de innumerables sucesos violentos en el subcontinente asiático. Dentro de dicho contexto, abogar por el yoga no puede leerse exclusivamente como un acto de buena voluntad, sino como una tentativa por enarbolar el estandarte de una identidad cultural y religiosa en detrimento de otras que también habitan en el sur de Asia. La apuesta fue la de ofrecer al mundo un producto icónico que resumiera la fortaleza cultural de India: en otras palabras, políticos y swamis impulsaron la idea de que "ahora el yoga es esencial no sólo para el hinduismo, sino también para el orgullo nacional." ${ }^{14}$ Es en este tenor que debemos situar las hostilidades suscitadas por el IDY.

Las críticas y posiciones apuntan en direcciones varias y hasta opuestas. Por un lado, Baba Ramdev declaró que la secuencia de los Saludos al Sol (los cuales se apoyan en ejercicios respiratorios) no implica ninguna actitud religiosa en concreto, y que no deberían mezclarse con la recitación de mantras; sostuvo además que el principal beneficio del yoga es fomentar la concentración y la cura de varias enfermedades. ${ }^{15}$ Ramdev buscaba sin duda asegurar la campaña de Modi. Por otro lado, voces cercanas a la derecha hindú, como Yogi Adityanath (dirigente del templo de Gorakhpur), han criticado fuertemente la decisión de excluir el sürya-namaskār de la celebración del primer IDY. Para Adityanath (quien también es miembro del Parlamento) el sūrya-namaskār es una parte primordial de la práctica del yoga; quien no quiera aceptar esto - continúa- debería alejarse del yoga y, de hecho, abandonar la India cuando no simplemente "ahogarse en el océano", pues el Dios Sol "es la fuente de toda la energía del mundo". ${ }^{16}$ Son declaraciones reaccionarias que sólo contribuyeron a agitar aún más las aguas de la campaña por el IDY.

Kumar 2015.

Panchkula 2015.

Simeon 2015.

PNS 2015.

Ali 2015. 
Si bien la práctica del sūrya-namaskār está ligada al Dios Sol (Sūrya), los orígenes de esta secuencia como parte integral de las rutinas de yoga no resulta tan clara. Ninguno de los textos de yoga, desde el Yogasūtra (circa siglo II), pasando por el Gorakșaśataka (ca. 1400) y hasta la Gheraṇdasaṃhitā (XVI-XVII), explica o menciona siquiera algo que se parezca a esta secuencia de posturas y respiraciones. Como han indicado varios autores, esta secuencia tiene sus orígenes en el palacio de Mysore, en la primera mitad del s.XX y fue desarrollada (de varios modos y con distintos énfasis) por personalidades como Krishnamacharya, Iyengar o Jois, a quienes con justa razón se les conoce como "padres del yoga moderno". ${ }^{17}$ Poner más atención a la tensión y la brecha existentes, pero no obvias, entre una práctica moderna y una apuesta por continuar una supuesta tradición añeja apunta, por un lado, a una falta de conocimiento del pasado y, por el otro, a intenciones de manipular artículos culturales con fines políticos. A veces, las nuevas formas de yoga también provocarán acusaciones por su falta de apego a la tradición, o rechazo a causa de confesiones religiosas particulares; en ambos casos se concibe el yoga como una práctica inherentemente "hindú". ${ }^{18}$ Ambos fenómenos pueden articularse conjuntamente, desde luego.

Ahora bien: la elección del 21 de junio no es casual: se trata del solsticio de verano y del día más largo del año, razón por la cual el sol brilla más. Esto hace inferir que la integración del sūrya-namaskār estaba considerada por los organizadores de la celebración y por el propio Modi desde los albores de la campaña por el IDY. De hecho, casi todas las imágenes promocionales sugieren o evocan de manera explícita a una persona que hace reverencias al sol. Las reacciones suscitadas obligaron a dar marcha atrás a su inclusión en el programa del 21 de junio de 2015, aunque las tensiones no se eliminaron del todo.

Otro punto de controversia relacionada se refiere a los esfuerzos gubernamentales por introducir clases de yoga en los niveles educativos básicos, con el fin de mejorar el adiestramiento físico de los niños. ¿Qué objeción podría haber? Si el yoga aporta beneficios a la salud, a primera vista resulta positiva su implementación en las escuelas. Bueno, uno de los puntos en jaque es que a menudo la práctica del yoga va acompañada de la repetición del mantra OM, una sílaba sagrada en especial para los hindúes. Como con el sūrya-namaskār, la sílaba OM conlleva una inequívoca orientación religiosa que ha resultado incómoda sobre todo para algunos sectores musulmanes. El hecho de que sus hijos sean instados a repetir palabras como hari y om, o a hacer los Saludos al Sol, es experimentado como una afrenta que hiere sus sensibilidades religiosas, puesto que representa un culto completamente ajeno a las estipulaciones del Corán.

$\mathrm{Si}$, como parecer ser, detrás de la concepción del yoga propulsada por la campaña del IDY se encuentran las nociones de Iyengar y otros difusores afines, no debemos perder de vista el hecho de que tanto Iyengar como Jois "presentaban sus respectivas visiones del yoga [situadas] claramente dentro de un contexto filosófico y religioso." ${ }^{\prime 9}$ Esta asociación es muy difícil de pasar por alto, sobre todo dentro del subcontinente. Para algunos sectores no hinduistas, la propaganda del IDY fue

\footnotetext{
17 Véase Singleton, Narasimhan y Jayashree 2012, 337. Norman Sjoman produjo el estudio clásico sobre el palacio de Mysore: The Yoga Tradition of the Mysore Palace, Abhinav Publications, Nueva Delhi, 1996.

Jain 2014, 429.

19 Sarbacker 2014, 104.
} 
no sólo incómoda, sino aun vista con recelo y sospecha. De este modo, el AIMPLB celebró un conclave en agosto de 2015 donde se atendió este asunto de manera particular; en esa ocasión, uno de los oradores declaró que: "Hay una seria amenaza a nuestra religión. Existe un propósito siniestro de imponer el "dharma brahmán" a través del yoga, el surya namaskar y la cultura védica. Todo ello está en contra de las creencias islámicas. ${ }^{20} \mathrm{Si}$ bien es altamente dudoso que el yoga, tal y como lo conocemos hoy en día, tenga una relación directa con la cultura védica (o, para el caso, la "antigüedad" de los Saludos al Sol), lo importante es la asociación inmediata que se establece en la mente del público. Lo mismo sucede fuera de India; pero dentro, dicha asociación hace resonar melodías distintas: no las de una armonía exótica y espiritual, sino la cacofonía del enfrentamiento identitario.

Los voceros del gobierno y los organizadores del evento estuvieron tratando de asegurar al público que el acontecimiento buscaba invocar un orgullo nacional, más que resaltar alguna identidad religiosa en particular. "Es el inicio de una nueva era de paz y armonía", fueron las palabras de Modi al referirse a la decisión positiva de la ONU con respecto del Día Internacional del Yoga. Al considerar la historia de la India moderna y aun la carrera política de Modi, se puede inferir que el primer ministro indio cuenta con una agenda que no necesariamente considera la inclusión abierta de todas las comunidades religiosas en el sur de Asia. Esta es una agenda propulsada intensamente por la Asociación de Voluntarios Nacionales, o RSS, una organización nacionalista de ultraderecha en la cual ha militado Narendra Modi. Como apunta una reconocida figura intelectual en India: "Los representantes del RSS en el gobierno están tratando de imponer su versión de la cultura india, y su comportamiento indica que tratan a la cultura como un medio de dominación política". ${ }^{21}$ Al reflexionar sobre el yoga moderno, Stuart Sarbacker apunta lo siguiente:

Entre los que están fuera de un contexto indio, el yoga está asociado de manera positiva con lo exótico y lo espiritual; dentro de India, está asociado con la popularización de una tradición nativa, con un sentido de la importancia de la práctica como parte de una tradición hinduista de la renuncia. ${ }^{22}$

En otras palabras: mientras que para los simpatizantes globales la noción de yoga suscita ideas favorables y optimistas, para otros representa o insinúa una identidad cultural y religiosa indudable. Para algunos sectores, por consiguiente, la campaña por el IDY rezumaba imposición y ponía en entredicho la libertad de culto. De hecho, esto bien pudo haber sido una reacción anticipada y hasta esperada, pues "La RSS prospera con la animadversión. Se hubieran disgustado profundamente si los musulmanes no hubieran levantado objeciones contra la imposición del yoga." ${ }^{23}$ Para ponerlo una vez más de manera clara: por un lado, encontramos una cantidad considerablemente grande de personas en el mundo que vieron con buenos ojos la campaña por un IDY; por el otro, en la tierra natal del yoga, se produjeron recelos y se levantaron sospechas.

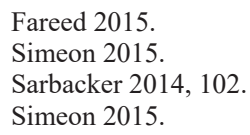




\section{La propaganda: el discurso y las nociones sobre el yoga}

Tras la iniciativa presentada por Narendra Modi ante las Naciones Unidas, y su posterior aceptación, tuvo lugar una propaganda muy fuerte para difundir el logro en torno del IDY. Hubo circulación de muchos videos promocionales con actores y figuras públicas en distintas plataformas, y en varias lenguas, que anticiparon e hicieron propaganda del evento del 21 de junio de 2015. Uno de los lemas con que se "vendió" al público en general el apoyo fue Live Life To Its Fullest, o "Vive la vida a plenitud". Por supuesto, el lema invoca el bienestar físico y espiritual que se cree puede proporcionar el yoga. Al mismo tiempo, y tomando en cuenta el discurso de Modi ante las naciones Unidas, se pueden escuchar ecos de un yoga integral, tal y como lo exponía Swami Yogendra, uno de los artífices del llamado neo-hathayoga. Yogendra pensaba que el yoga se relacionaba no sólo con el bienestar o la liberación individual, sino también con "el carácter seminal dentro de toda la sociedad de la humanidad". ${ }^{24}$ No es muy distinto de la tentativa de Modi por presentar el yoga como una solución idónea para los males del mundo. Es decir que el yoga que ofrece Modi no es el de Patañjali, sino el que se fue creando a partir de la confluencia de un sinfín de tendencias, ideologías y perspectivas desde más o menos fines del siglo XIX e inicios del siglo XX.

Simultáneamente -y por esto mismo-, siempre hay un espacio espectral, por así llamarlo, donde resulta ambigua la forma en que se trata de presentar el yoga. Recientemente se ha intentado también, con mayores bríos que antes, colocar el yoga en un espacio tanto de educación física como de práctica curativa. Así, el Viceministerio de Salud (āyus mantrālay) es un brazo gubernamental que velará por la proyección, salvaguardia y difusión del yoga, fundado apenas en noviembre de 2014. Este viceministerio tiene el interesante nombre de Ayurveda, Yoga, Unani, Siddha y Homeopatía (conocido como AYUSH). El AYUSH también se hará cargo de medicinas tradicionales y a su frente se encontrará Shripad Yesso Naik, quien tomó posesión de la nueva institución, hasta ahora encuadrada como departamento en el Ministerio de Salud. Si aquí se equipara el yoga con formas tradicionales de curación, ¿dónde queda su papel de disciplina corporal, acrobática y/o deportiva?

Involuntariamente, existe una especie de tensión acerca de cómo evaluar y entender el yoga en el contexto contemporáneo: ¿es una disciplina espiritual y mental, o un tipo de ejercicio o gimnasia, sujeto a las cargas tributarias respectivas y vigentes en algunas partes del mundo? ${ }^{25}$ De todo hay un poco, sin lugar a dudas. En la página oficial del gobierno de India para el IDY se muestra un desplegado o banner que reza: "El yoga no tiene que ver con ejercicio, sino con descubrir la sensación de unidad con nosotros, con el mundo y con la naturaleza." ${ }^{26}$ El énfasis aquí es en el papel apaciguador y armonioso del yoga, un remedio deseable para hacer frente a la creciente violencia alrededor del mundo. Esta idea está bien representada en el logotipo oficial del IDY, con la combinación de las hojas en colores verde y café y la

Singleton 2007, 137.

25 En 2014, en el estado de Washington, se impuso una tasa del 6\% a los institutos dedicados al yoga, a los gimnasios y otro tipo de centros de adiestramiento físico; algo que se conoce ahora como el "impuesto del yoga", o yoga tax (cfr. Martino 2015, 2).

26 De hecho, se trata de una cita de Modi extraída de su discurso ante la ONU. Cfr. Modi 2014, 5. 
silueta humana en pose de salutación y meditación. El Protocolo Común del Yoga, auspiciado por el AYUSH, apunta que el yoga es "una sutil ciencia que se centra en lograr la armonía entre la mente y el cuerpo" y que tiene la meta de "lograr la autorrealización". ${ }^{27}$ Narendra Modi expresó que la declaración del IDY representaba, "una nueva era de paz". Como indiqué antes, éste no fue exactamente el caso dentro de India misma. Sin embargo, para defenderse de las críticas de imposición religiosa, Ramdev declaró que el sürya-namaskār era un ejercicio. ${ }^{28}$ ¿Es, pues, sí o no un ejercicio? ¿Un ejercicio pude ser una ciencia? ¿Hasta qué grado una ciencia puede fungir como herramienta para la paz?

En la amalgama de nociones en torno del yoga que está presente tanto en el discurso de Modi como en las páginas oficiales del IDY, podemos encontrar una continuación de la combinación de los discursos elaborados por personalidades como Iyengar, entre otros difusores modernos del yoga. Algunos estudiosos han advertido cómo este maestro de yoga "desarrolló múltiples niveles de discurso que correspondían a los énfasis relativos en las implicaciones físicas, energéticas o mentales de la práctica yóguica, una especie de dinámica exotérica-esotérica [...] que se desprende de la perfección de la fundamentación del āsana del yoga". ${ }^{29}$ Esta misma dinámica es la que, consciente o inconscientemente, invocó Modi en sus palabras ante la ONU en Nueva York, y es el mismo sentido que reprodujo Ban Ki-moon a la postre. A final de cuentas, es también el sentido al que el público en general -pero sobre todo los practicantes- responde en lo que concierne al yoga moderno.

La cuestión de los âsanas o posturas resulta clave para entender el yoga moderno. Se trata, en gran medida, de un yoga postural que se apoya enormemente en el perfeccionamiento de varias y difíciles posturas físicas. El antecedente más obvio es el hathayoga, pero filtrado a través de las metodologías desarrolladas por el propio Iyengar, Krishnamacharya o Pattabhi Jois, entre otros, ya en pleno siglo XX. El énfasis corporal se ha visto forzado a dialogar con formas de yoga más meditativas. De hecho, la amalgama discursiva los funde: "La transformación del yoga moderno en una entidad transnacional, una que se extiende a través de las fronteras culturales y geográficas, posee raíces en el zeitgeist cosmopolitano de la India en la primera mitad del siglo XX," ${ }^{30}$ donde confluyeron el discurso científico, la calistenia y otros factores como el nacionalismo militante ${ }^{31}$ y hasta una suerte de darwinismo social además de la eugenesia. ${ }^{32}$ Quizá un aspecto importante que también debe destacarse, es que esta modalidad moderna opera casi por completo a través de la lengua inglesa, razón por la cual Mark Singleton opta por hablar de un "yoga transnacional anglófono" en lugar de simplemente un "yoga moderno". ${ }^{33}$

Aunque hay un intento por presentar al yoga como una metodología que ofrece beneficios físicos, en las citas de la campaña del IDY claramente se acentúa su carácter pacificador, justo para poder circunscribirlo dentro del discurso global sobre la paz. Sin embargo, ello no evita que en distintas latitudes haya personalidades, incluso funcionarios, del mundo deportivo que lo apoyan. Como mencioné al principio de

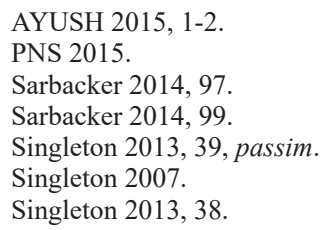


este texto, en la celebración de la Ciudad de México estuvo presente el representante del Instituto del Deporte; en comparación, la presencia de personalidades religiosas $o$ activistas pacifistas fue insignificante.

En los discursos tanto oficiales como populares en torno del yoga, encontramos un énfasis en las palabras o nociones de "deporte" y "mente", pero hay una clara ambigüedad al respecto: ciertamente es una disciplina más o menos corporal que puede aportar beneficios físicos, pero al mismo tiempo también se le asocia con beneficios "mentales", con lo que se entra en terrenos espirituales. Aunque fuera del sur de Asia la gente cada vez más ve el yoga como una disciplina física, lo cierto es que en India posee claras implicaciones religiosas. El yoga secular es en gran medida un fenómeno moderno y "occidental" que ha terminado por influir en algunos sectores en el sur de Asia. Al mismo tiempo, tampoco se puede negar la influencia del "efecto pizza" en los centros urbanos de India, donde también cada vez más se puede acudir a "estudios de yoga" donde hay instructores, y no yoguis renunciantes, a cargo de las sesiones.

El yoga se ha convertido sin duda en un artículo cultural reconocible en todo el orbe: ahora resulta más claro que nunca. Su estatus, además, parece estar más encumbrado que otras prácticas ligeramente afines, como el karate o el kung-fu, que están indefectiblemente enmarcadas como disciplinas marciales. Pero no podemos dejar de advertir las diferentes nociones en torno del yoga que parecen confluir, no siempre de manera armónica, en los discursos transnacionales, sobre todo dentro de la campaña por el IDY. Quizá lo más evidente es que no hay un solo yoga: “Gracias a su posición dentro de un nexo dinámico y transnacional de conocimiento y práctica, en el cual discursos divergentes compiten por la primacía, tiene poco sentido hablar de un solo yoga unitario". ${ }^{34} \mathrm{Al}$ hacer del yoga un motivo de celebración en el calendario global reconocido por la ONU, se abre la incógnita de a quién le pertenece el yoga. Es diferente la situación de los artículos, tradiciones o actividades declarados como patrimonio de la humanidad. En aquellos casos, la UNESCO reconoce un valor inmaterial y no cuantificable en componentes particulares de una cultura nacional en específico.

\section{Conclusiones: cuestiones para seguir considerando}

La instauración de un día dedicado especialmente al yoga puede hacernos inferir varias cosas, las cuales se deben ir aquilatando de manera cuidada y sensata. Mientras algunos puntos resultan obvios -aunque esconden implicaciones importantes-, otros resultan menos evidentes y suponen problemáticas serias que atañen tanto a la historia de las religiones, como a la política contemporánea.

La actual administración de India ha demostrado poseer cualidades de liderazgo e influencia política innegables, pues no tomó más de tres meses después del discurso de Modi para que las Naciones Unidas decretaran el IDY. El soft power o "poder blando" de India parece estar abriéndose paso de manera firme, al tiempo que el crecimiento económico del país no quiere perder terreno ante la otra potencia asiática, es decir China. Antes de bajar del podio el 21 de junio de 2015, Modi dijo que ese día

34 Singleton 2013, 54. 
no habría un solo lugar en el mundo que no fuera alcanzado por el yoga ${ }^{35}$ No sólo se trata de una analogía con el sol, sino que constituye una manera bastante metafórica de referirse a las esperanzas de una potencial influencia india en el mundo político y económico, del alcance de su poder blando. Hace apenas unos años, a inicios de enero de 2014, el ya mencionado Baba Ramdev sostuvo que Modi había demostrado su liderazgo. ${ }^{36}$ Dos años después, las palabras de Ramdev parecen resultar aún más ciertas.

Este logro diplomático, al parecer inocuo, representa una manera bastante sutil de insertarse en el discurso internacional en favor de la paz, pero en particular en el que censura categóricamente el terrorismo, por definición violento. En el discurso ante la ONU, Modi dijo que "La antigua sabiduría de la India mira al mundo como una sola familia". Habló entonces de una necesidad de fomentar y estrechar lazos fraternales entre las naciones, en parte para hacerle frente al terrorismo en el mundo. Juntos, señaló Modi, tenemos que trabajar en pos de una "paz genuina". No obstante, como he señalado, en el ámbito nacional lo que se generó a partir de la campaña por el IDY fue desazón y malestar social, un resultado que seguramente el gobierno de Modi tenía previsto.

El interés de Modi por lograr un reconocimiento como éste puede tener diversas motivaciones o implicaciones. Enumeraré cuatro:

a) La búsqueda de Modi por dejar una fuerte impronta en la cultura global.

b) Un apoyo tácito a la "hinduidad" (hindutva) de la India por encima de otros grupos religiosos y culturales.

c) El supuesto de que el legado cultural de India puede operar como un ítem comercial de alcances inmensos: tan sólo en los Estados Unidos, el yoga representa ganancias de alrededor de 27 mil m.d.d. ${ }^{37}$ Nótese que en su gira de 2016 en Latinoamérica, la cantante Madona solicitó los siguientes lujos, facilidades y artículos: candelabros de oro, manteles de seda, treinta guardaespaldas, un acupunturista, un monitor de yoga y varios chefs de comida vegetariana, entre otras $\operatorname{cosas}^{38}{ }^{38}$ (La dieta y la salud, pues, son artículos comercializables y lujosos). Podría decirse que el yoga, junto con las especias y el cine de Bollywood, exigen del mundo una suerte de regalías simbólicas y políticas, y el gobierno de Modi pretende cobrarlas. No olvidemos tampoco que el fenómeno de lo que podríamos llamar "turismo yóguico" se traduce en grandes beneficios económicos para sitios y centros de capacitación como Rishikesh.

d) El yoga transnacional es un fenómeno impreciso que brota de una amalgama de factores e ideas preconcebidas, donde el acento puede transitar de lo espiritual a lo corporal, de lo autóctono a lo global, según las necesidades del momento o de quien invoque el yoga en su discurso.

Los puntos de reflexión que he señalado forman una parte importante de una agenda política y cultural del aparato gubernamental de la India y muy posiblemente de la derecha hindú. Atañe, sin embargo, a todo el país surasiático de manera directa, como demuestran las tensiones que este acontecimiento ha suscitado. Además, 1la-

Bhattacharya 2015.

Niti Central 2014.

TNN \& Agencies 2015.

Mi énfasis. http://www.lavanguardia.com/vida/20160106/301233208716/oro-flores-yoga-y-acupuntura-las-ex centricidades-de-madonna-en-mexico.html 
man la atención las formas en que se ha tratado de invocar una supuesta esencia del yoga. Para la Historia de las Religiones, este capítulo condensa una larga trayectoria de definiciones y redefiniciones, pero que se proyectan de modos novedosos. Otras disciplinas bien pueden tratar de lidiar con este asunto a través de las articulaciones del poder blando, un aspecto que no se ha desarrollado aquí. Lo que he intentado sobre todo es indicar que el tema del IDY encierra diversas aristas y, en consecuencia, he querido sugerir posibles rutas de análisis.

Por tratarse de un tema tan reciente, no contamos aún con suficientes evaluaciones. Falta reunir mayor cantidad de evidencias y material relevante, pero también falta aguardar por los modos en que este nuevo capítulo en la historia del yoga irá desenvolviéndose. Si bien hay una cantidad importante de notas de prensa, es necesario elaborar estudios más profundos que permitan imprimir marcos teóricos apropiados y comprensivos. No sólo se trata de entender los mecanismos políticos que han entrado en juego, sino también de poder evaluar con juicio y un panorama amplio los modos como situar este nuevo avatar del yoga en su larga historia. Este yoga - o yogas- que es ahora de todos nos invita a concertar miradas y críticas finas e introspectivas. Fiel a su historia, el yoga continúa siendo una tradición en constante transformación, una que a su vez transforma el entorno internacional y redefine las categorías de paz, bienestar y poder cultural.

\section{Bibliografía}

M. Ali, "Those who want to avoid Yoga can leave India: Yogi Adityanath", The Hindu, 9 de junio de 2015, http://www.thehindu.com/news/national/other-states/ yogi-adityanath-says-those-who-avoid-yoga-can-leave-india/article 7297946.ece [acceso: 20/06/15].

T. Ap, "India ties itself in knots over International Yoga Day", $C N N, 21$ de junio de 2015, http://edition.cnn.com/2015/06/19/world/international-yoga-day/index. html [acceso: 22/06/15].

AYUSH, Common Yoga Protocol, Government of India, New Delhi, 2015, http://idy. nhp.gov.in/UploadFiles/files/jk_IDY\%20common\%20yoga\%20protocol_book. pdf

S. Bhattacharya, "Bend it like Narendra: Modi turns to tradition with Yoga", The Wall Street Journal, 21 de junio de 2015, http:/www.wsj.com/articles/bend-it-likenarendra-modi-turns-to-tradition-with-yoga-1434874237 [acceso: 21/06/15].

M.F. Fareed, "AIMPLB calls conclave to push its fight against "Vedic culture, Brahmni dharma'", The Indian Express, 13 de Agosto de 2015: http://indianexpress.com/article/cities/lucknow/aimplb-calls-conclave-to-push-its-fight-against-vedic-culture-brahmin-dharma/ [acceso: 05/02/16].

S. Fenton, "International Yoga Day controversy as India is accused of pushing 'Hindu agenda' on Muslims", The Independent, 21 de junio de 2015, http://www.indepen dent.co.uk/news/world/asia/international-yoga-day-controversy-as-india-is-accu sed-of-pushing-hindu-agenda-on-muslims-10334532.html [acceso: 04/02/16].

International Day of Yoga, página oficial del gobierno de India, http://idayofyoga. org/index.php?route $=$ common/home

International Day of Yoga, sitio oficial de la Organización de las Naciones Unidas, http:/www.un.org/en/events/yogaday/background.shtml 
B.Ki-moon, "Message ofUN Secretary-GeneralBanKi-moon", UNIC/PRESSRelease, 13 de junio de 2015, http://www.unic.org.in/display.php?E=14004\&K=Yoga [acceso: 22/06/15].

S. Kumar, "International Yoga Day sparks controversy in India", The Diplomat, 20 de junio de 2015, http://thediplomat.com/2015/06/international-yoga-daysparks-controversy-in-india/ [acceso: 20/06/15].

A.R. Jain, "Who Is To Say Modern Yoga Practitioners Have It All Wrong? On Hindu Origins and Yogaphobia", Journal of the American Academy of Religion, 82, 2 (June 2014), 427-471.

G. Martino, “¿El yoga patas para arriba? Prolongación e inflexiones del Yoga desde la India antiguas hasta el mundo actual", Semana de Asia y el Pacífico, Mesa redonda sobre Estudios de la India, Universidad Nacional de La Plata (27-29 de agosto de 2015).

N. Modi, "Statement", General Debate of the $69^{\text {th }}$ Session of the United Nations General Assembly, New York, septiembre de 2014, http://www.un.org/en/ga/69/ meetings/gadebate/pdf/IN_en.pdf [acceso: 23/06/15].

L. Moftah, "International Yoga Day 2015: Watch summer solstice live stream in New York Time's Times Square with Sri Sri ravi Shankar", IBT, 21 de junio de 2015, http://www.ibtimes.com/international-yoga-day-2015-watch-summersolstice-live-stream-new-yorks-times-square-1975868 [acceso: 14/07/15].

Niti Central, "Modi has proved his leadership: Baba Ramdev", Hindu Janajagruti Samiti, 5 de enero de 2016, https://www.hindujagruti.org/news/18470.html [acceso: 08/01/16].

Panchkula, "Ramdev lauds Muslims for supporting International Yoga Day", Hindustan Times, 15 de junio de 2015, http:/www.hindustantimes.com/punjab/ ramdev-lauds-muslims-for-supporting-international-yoga-day/story-IHnWMVJMuItRjJ5E8BrN0K.html [acceso: 05/02/16].

PNS, "Surya namaskar is an exercise", The Pioneer, 16 de junio de 2015, http:// www.dailypioneer.com/state-editions/chandigarh/surya-namaskar-is-an-exer cise.html [acceso: 05/02/16].

Ch. Rajghatta, "Narendra Modi calls for International Yoga Day", The Times of India, 28 de septiembre de 2014, http://timesofindia.indiatimes.com/india/Narendra-Modi-calls-for-International-Yoga-Day/articleshow/43665102.cms [acceso: 18 de junio de 2015].

S.R. Sarbacker, "Reclaiming the spirit through the body: The nascent spirituality of Modern postural yoga", Interdisciplinary Journal for the Study of Religious Contact and Transfer 1 (2014), 95-114.

D. Simeon, "Yoga, by RSS", The Indian Express, 16 de junio de 2015, http://indianexpress.com/article/opinion/columns/yoga-by-rssit-would-have-been-upsethad-muslims-not-objected-to-compulsory-yoga/ [acceso: 04/02/16].

M. Singleton, "Transnational exchange and the genesis of modern postural Yoga", Yoga Traveling: Bodily Practice in Transcultural Perspective. Ed. B. Hauser, Springer, Heidelberg, 2013, 37-56.

- "Yoga, eugenics, and spiritual Darwinism in the early twentieth century", International Journal of Hindu Studies 11, 2 (2007), 125-146.

M. Singleton, M. Narasimhan y M.A. Jayashree, "Yoga Makaranda of T. Krishnamacharya", Yoga In Practice. Ed. D.G. White, Princeton University Press, Princeton y Oxford, 2012, 337-352. 
TNN \& Agencies, "PM Modi seeks to turn yoga record on its head as India stretches soft power", The Times of India, 21 de junio de 2015, http://timesofindia.indiatimes.com/ india/PM-Modi-seeks-to-turn-yoga-record-on-its-head-as-India-stretches-softpower/articleshow/47756880.cms?utm_source=TOInewHP_TILwidget\&utm medium=ABtest\&utm_campaign=TOInewHP [acceso: 04/02/16]. 